\title{
Exocyclic Sulfur and Selenoorganic Compounds Towards Their Anticancer Effects: Crystallographic and Biological Studies
}

\author{
EWA ŻESŁAWSKA ${ }^{1}$, ANNAMÁRIA KINCSES ${ }^{2}$, VIVIEN UNGER ${ }^{2}$, VIKTOR TÓTH ${ }^{2}$, \\ GABRIELLA SPENGLER $^{2}$, WOJCIECH NITEK ${ }^{3}$ and WALDEMAR TEJCHMAN ${ }^{1}$ \\ ${ }^{1}$ Department of Chemistry, Institute of Biology, Pedagogical University of Cracow, Kraków, Poland; \\ ${ }^{2}$ Department of Medical Microbiology and Immunobiology, Faculty of Medicine, \\ University of Szeged, Szeged, Hungary; \\ ${ }^{3}$ Faculty of Chemistry, Jagiellonian University, Kraków, Poland
}

\begin{abstract}
Background/Aim: Multidrug resistance leads to therapeutic difficulties. There is great interest in experimental chemotherapy regarding multidrug resistance inhibitors and new anticancer agents. The aim of this study was to evaluate the anticancer activity of exocyclic sulfur and selenoorganic compounds on mouse T-lymphoma cell lines. Materials and Methods: A series of eighteen sulfur and selenium analogues of $2[1 \mathrm{H}]$-pyrimidinone and hydantoin derivatives were evaluated towards their efflux modulating, cytotoxic and antiproliferative effects in mouse T-lymphoma cells. The combination assay with doxorubicin on multidrug resistant mouse T-lymphoma cells was performed in order to see the nature of drug interactions. Crystal structures were determined for two selected compounds with the highest efflux-modulating activity. Results: The sulfur analogues with aromatic rings almost perpendicular to pyrimidinethione ring at positions 1 and 6 showed the highest efflux inhibitory action, while all selenium analogues showed good antiproliferative and cytotoxic activities. Conclusion: The sulfur analogues can be modified towards improving their efflux inhibitory activity, whereas the selenium towards antiproliferative and cytotoxic activities.
\end{abstract}

Cancer is still a major human health problem leading very often to mortality. According to WHO data, cancer as the second leading cause of death, was responsible for approximately 14 million new cases in the year 2012 and

Correspondence to: Ewa Żesławska, Department of Chemistry, Institute of Biology, Pedagogical University of Cracow, Podchorążych 2, 30-084 Kraków, Poland. Tel: +48 126627882, e-mail: ewa.zeslawska@up.krakow.pl

Key Words: Pyrimidinethione, pyrimidineselenone, thiohydantoin, selenohydantoin, crystal structure, P-gp inhibitor, antiproliferative activity, combination assay with doxorubicin. killed 8.8 million people in 2015 (1). There is still a need to search for new anticancer drugs, due to the increasing multidrug resistance leading to therapeutic difficulties.

There is great interest in experimental chemotherapy regarding multidrug resistance (MDR) inhibitors. The cellular overproduction of MDR efflux pumps for example ABCB1 (P-glycoprotein, P-gp) is one of the more relevant mechanisms underlying MDR, which is capable to promote the efflux of cytotoxic drugs out of the cells (2). ABCB1 belongs to the ATP-binding cassette $(\mathrm{ABC})$ transporter proteins, involved in the transport of various substrates $e . g$. cholesterol, drugs, chloride ion, toxins, across membranes (3). In cancer cells, the overexpression of ABCB1 is responsible for reduction of the intracellular concentration of the anticancer drugs, which in consequence leads to treatment failure (4). It should be pointed out that several clinical trials targeting ABCB 1 with small molecules, firstgeneration (verapamil, cyclosporine A, quinidine) $(5,6)$, second-generation (dexverapamil, cinchonine, valspodar) (7, 8) and third-generation (zosuquidar, tariquidar, laniquidar) inhibitors have failed due to their toxicity $(9,10)$. Finding non-toxic inhibitors, capable of decreasing the ABCB1mediated drug efflux, is a promising strategy for improving the effectiveness of cancer treatment.

Recently, a number of different compounds were designed as potential MDR modulators, including new chemical groups of $\mathrm{ABCB} 1$ inhibitors, i.e. derivatives of xanthone (11), benzoxanthone (12), hydantoin and thiohydantoin (13, 14), benzodipyranone (15), indol alkaloid (16), selenoesters $(17,18)$, epigallocatechin and dihydromyricetin (19).

Taking this into consideration, we decided to evaluate eighteen sulfur and selenium analogues of $2[1 H]$-pyrimidinone (1-8) and hydantoin (9) derivatives (Figure 1) towards their efflux modulating, cytotoxic and antiproliferative effects in sensitive and resistant mouse T-lymphoma cells. Furthermore, the selected compounds were investigated in combination with the anticancer drug doxorubicin. The aim of our study was to 
compare the biological activity of sulfur and selenium compounds and to analyze crystal and molecular structures in the search of a structural feature that can be responsible for their activity.

The investigated compounds were synthesized according to the procedures published earlier $(20,21)$. In this paper, two new crystal structures of selected $2[1 H]$-pyrimidinethione derivatives are reported: 4-methyl-1-(4-methylphenyl)-6phenyl-2[1H]-pyrimidinethione (3S) and 4-methyl-1-(4methoxyphenyl)-6-phenyl-2[1H]-pyrimidinethione (4S). These compounds differ in the substituent at the aromatic ring and show the best activity towards inhibition of ABCB1, wherein the activity of $\mathbf{4 S}$ is 3 -fold higher than that of $\mathbf{3 S}$. The arrangement of rings may be related to the biological activity. In order to see mutual orientation of all three rings, a deeper insight into the structural properties of the presented compounds was performed with the use of X-ray diffraction analysis. Moreover, we compared crystal structures of active compounds with the known crystal structure of the not active compound 1S (22). We present the results of the biological studies of sulfur (1S-9S) and selenium (1Se-9Se) analogues of pyrimidinone and hydantoin derivatives (Figure 1) in order to see how the change of the sulfur atom to selenium can influence the $\mathrm{ABCB} 1$ inhibition, cytotoxic and antiproliferative activities.

\section{Materials and Methods}

Crystal structures determination. Crystals suitable for X-ray structure analysis were obtained from ethanol solution by slow evaporation of the solvent at room temperature. The intensity data were collected on the Bruker-Nonius Kappa CCD four circle diffractometer equipped with a Mo (0.71069 $\AA$ ) $\mathrm{K} \alpha$ radiation source. The phase problem was solved by direct methods using SHELXS and the structures were refined by SHELXL (23) programs. For molecular graphics MERCURY (24) program was used.

Compound 3S: $\mathrm{C}_{18} \mathrm{H}_{16} \mathrm{~N}_{2} \mathrm{~S}, \mathrm{M}_{\mathrm{r}}=292.39$, crystal size $=0.04 \times 0.18 \times$ $0.41 \mathrm{~mm}^{3}$, monoclinic, space group $\mathrm{P} 2{ }_{1} / \mathrm{c}, \mathrm{a}=10.9600(2) \AA$, $\mathrm{b}=25.4850(5) \AA, \mathrm{c}=12.9280(2) \AA, \beta=121.028(1)^{\circ}, \mathrm{V}=3094.3(1) \AA^{3}$, $\mathrm{Z}=8, \mathrm{~T}=100(2) \mathrm{K}, 22,417$ reflections collected, 7,059 unique reflections [Rint $=0.0474], \mathrm{R} 1=0.0429, \mathrm{wR} 2=0.0870$ [I $>2 \operatorname{sigma}(\mathrm{I})]$.

Compound $4 \mathrm{~S}: \mathrm{C}_{18} \mathrm{H}_{16} \mathrm{~N}_{2} \mathrm{OS}, \mathrm{M}_{\mathrm{r}}=308.39$, crystal size $=0.17 \times 0.36 \times$ $0.55 \mathrm{~mm}^{3}$, monoclinic, space group $\mathrm{P} 21 / \mathrm{c}, \mathrm{a}=12.6920(3) \AA$, $\mathrm{b}=8.9240(2) \AA, \mathrm{c}=16.8230(3) \AA, \beta=125.283(2)^{\circ}, \mathrm{V}=1555.42(7) \AA^{3}$, $\mathrm{Z}=4, \mathrm{~T}=100(2) \mathrm{K}, 12217$ reflections collected, 3556 unique reflections $\left[\mathrm{R}_{\mathrm{int}}=0.0334\right], \mathrm{R} 1=0.0346, \mathrm{wR} 2=0.0849$ [I $\left.>2 \operatorname{sigma}(\mathrm{I})\right]$.

CCDC 1833588 and 1833589 contain the supplementary crystallographic data for $\mathbf{3 S}$ and $\mathbf{4 S}$, respectively. These data can be obtained free of charge from The Cambridge Crystallographic Data Centre via www.ccdc.cam.ac.uk/data_request/cif.

Biological assays

Cell lines. The L5178Y mouse T-lymphoma cells (PAR) (ECACC Cat. No. 87111908, obtained from FDA, Silver Spring, MD, USA) were transfected with $\mathrm{pHa}$ MDR1/A retrovirus (25). The ABCB1expressing cell line L5178Y (MDR) was selected by culturing the infected cells with colchicine. L5178Y (parent) mouse T-cell lymphoma cells and the L5178Y human ABCB1 transfected subline were cultured in McCoy's 5A medium (Sigma-Aldrich, Steinheim, Germany) supplemented with $10 \%$ heat-inactivated horse serum (Sigma-Aldrich), $200 \mathrm{mM}$ L-glutamine (Sigma-Aldrich) and a penicillin streptomycin (Sigma-Aldrich) mixture in concentrations of $100 \mathrm{U} / \mathrm{l}$ and $10 \mathrm{mg} / \mathrm{l}$, respectively.

Rhodamine-123 (R123) accumulation assay by flow cytometry. The cell number of L5178Y MDR and L5178Y parental cell lines were adjusted to $2 \times 10^{6}$ cells $/ \mathrm{ml}$, re-suspended in serum-free McCoy's $5 \mathrm{~A}$ medium and distributed in $0.5 \mathrm{ml}$ aliquots into Eppendorf centrifuge tubes. The tested compounds were added at 2 and $20 \mu \mathrm{M}$ concentrations and the samples were incubated for $10 \mathrm{~min}$ at room temperature. Verapamil (purity: $\geq 99 \%$; Sigma-Aldrich) was applied as positive control. DMSO at $2 \%$ was also added as solvent control. Next, $10 \mu \mathrm{l}(5.2 \mu \mathrm{M}$ final concentration) of the fluorochrome and ABCB1 substrate R123 (Sigma-Aldrich) were added to the samples and the cells were incubated for further 20 min at $37^{\circ} \mathrm{C}$, washed twice and re-suspended in $0.5 \mathrm{ml}$ PBS for analysis. The results obtained from a representative flow cytometry experiment measuring 20,000 individual cells of the population were evaluated using Partec CyFlow ${ }^{\circledR}$ flow cytometer (Partec, Münster, Germany). The percentage of mean fluorescence intensity was calculated for the treated MDR cells as compared with the untreated cells. A fluorescence activity ratio (FAR) was calculated based on the following equation which relates to the measured fluorescence values:

$$
\mathrm{FAR}=\frac{\mathrm{MDR}_{\text {treated }} / \mathrm{MDR} \text { control }}{\text { parental treated } / \text { parental } \text { control }}
$$

Assay for cytotoxic and antiproliferative effect. The compounds were diluted in a volume of $100 \mu \mathrm{l}$ medium. Then, $1 \times 10^{4}$ cells (for cytotoxic assay) and $6 \times 10^{3}$ (for antiproliferative assay) in $100 \mu \mathrm{l}$ of medium were added to each well, with the exception of the medium control wells (17). The culture plates were incubated at $37^{\circ} \mathrm{C}$ for 24 and $72 \mathrm{~h}$; at the end of the incubation period, $20 \mu \mathrm{l}$ of MTT (thiazolyl blue tetrazolium bromide; Sigma-Aldrich) solution (from a $5 \mathrm{mg} / \mathrm{ml}$ stock) were added to each well. After incubation at $37^{\circ} \mathrm{C}$ for $4 \mathrm{~h}, 100 \mu \mathrm{l}$ of SDS (sodium dodecyl sulfate; Sigma-Aldrich) solution $(10 \%$ in $0.01 \mathrm{M} \mathrm{HCI})$ were added to each well and the plates were further incubated at $37^{\circ} \mathrm{C}$ overnight. Cell growth was determined by measuring the optical density (OD) at $540 \mathrm{~nm}$ (ref. $630 \mathrm{~nm}$ ) with Multiscan EX ELISA reader (Thermo Labsystems, Cheshire, WA, USA). Inhibition of the cell growth was determined according to the formula:

$$
100-\left[\frac{\mathrm{OD}_{\text {sample }}-\mathrm{OD}_{\text {medium control }}}{\mathrm{OD}_{\text {cell control }}-\mathrm{OD}_{\text {medium control }}}\right] \times 100
$$

Checkerboard combination assay. The dilutions of doxorubicin (2 $\mathrm{mg} / \mathrm{ml}$, Teva Pharmaceuticals, Budapest, Hungary) were made in a horizontal direction in $100 \mu \mathrm{l}$, and the dilutions of the resistance modifiers vertically in the microtiter plate in $50 \mu \mathrm{l}$ volume. The L5178Y MDR mouse T-lymphoma cells were re-suspended in culture medium and distributed into each well in $50 \mu$ l containing $6 \times 10^{3}$ cells, with the exception of the medium control wells, to a 


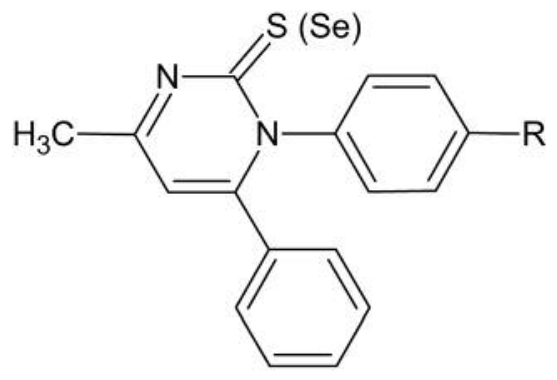

1S, 1Se: $\mathrm{R}=-\mathrm{H}$

2S, 2Se: $\mathrm{R}=-\mathrm{Cl}$

3S, 3Se: $\mathrm{R}=-\mathrm{CH}_{3}$

4S, 4Se: $\mathrm{R}=-\mathrm{OCH}_{3}$

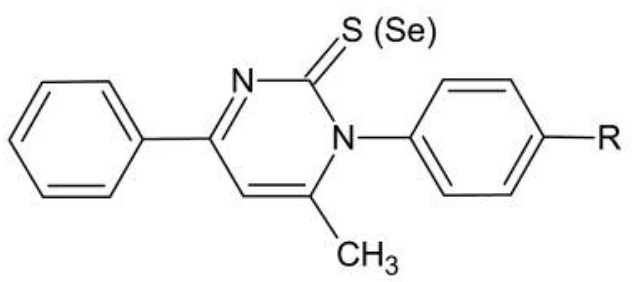

$5 S, 5 S e: R=-H$

6S, $6 \mathrm{Se}: \mathrm{R}=-\mathrm{Cl}$

7S, 7Se: $\mathrm{R}=-\mathrm{CH}_{3}$

8S, 8Se: $\mathrm{R}=-\mathrm{OCH}_{3}$<smiles>O=C1/C(=C\c2ccc(Cl)cc2)NC(=S)N1c1ccccc1</smiles>

9S, 9Se

Figure 1. Chemical structures of investigated compounds.

final volume of $200 \mu \mathrm{l}$ per well. The plates were incubated for $72 \mathrm{~h}$ at $37^{\circ} \mathrm{C}$ in a $\mathrm{CO}_{2}$ incubator and at the end of the incubation period, the cell growth was determined by the MTT staining method, as earlier described. Drug interactions were evaluated using CompuSyn software. Combination index $(\mathrm{CI})$ values at $50 \%$ of the growth inhibition dose (ED50), were determined using CompuSyn software (www.combosyn.com, ComboSyn, Inc., Paramus, NJ, USA) to plot four to five data points to each ratio. CI values were calculated by means of the median-effect equation, where $\mathrm{CI}<1, \mathrm{CI}=1$, and $\mathrm{CI}>1$ represent synergism, additive effect (or no interaction), and antagonism, respectively.

\section{Results}

Crystal and molecular structures. The projections of molecular geometry in the crystal structures with the atom numbering are shown in Figure 2. The asymmetric unit of $3 \mathrm{~S}$ consists of two independent molecules (one molecule is labeled as $\mathrm{A}$, the second as $\mathrm{B}$ ), while $\mathbf{4 S}$ one molecule.

The angle between the plane of $2[1 H]$-pyrimidinethione ring and the plane of aromatic ring at $\mathrm{N} 1$ atom is $67.02(6)^{\circ}$, $78.27(6)^{\circ}$ and $82.82(5)^{\circ}$, whereas between the plane of $2[1 H]$-pyrimidinethione ring and aromatic ring at C6 is $56.14(7)^{\circ}, 64.24(6)^{\circ}$ and $76.16(5)^{\circ}$ for $\mathbf{3 S}$ molecule A, 3S molecule $\mathrm{B}$ and $\mathbf{4 S}$, respectively. The angle between the planes of two aromatic rings is $59.95(6)^{\circ}, 66.27(6)^{\circ}$ and $62.27(5)^{\circ}$ for $3 \mathrm{~S}$ molecule $\mathrm{A}, \mathbf{3 S}$ molecule $\mathrm{B}$ and $\mathbf{4 S}$, respectively.

The selected torsion angles, observed in the crystal structures of 1,6-diphenyl-2[1H]-pyrimidinethione derivatives presented in this paper and determined earlier (22), are listed in Table I. The comparison of them shows the slight differences of mutual orientations of aromatic rings and $2[1 H]$-pyrimidinethione ring.
Table I. The comparison of selected torsion angles $\left[{ }^{\circ}\right]$ for 1,6-diphenyl2[1H]-pyrimidinethione derivatives.

\begin{tabular}{lccrr}
\hline Torsion angle & 1S & 3S (A) & 3S (B) & 4S \\
\hline C2-N1-C7-C8 & $-81.0(1)$ & $-70.9(2)$ & $-80.7(2)$ & $-85.6(2)$ \\
C2-N1-C7-C12 & $100.7(1)$ & $110.3(2)$ & $98.2(2)$ & $97.4(2)$ \\
N1-C6-C13-C14 & $-68.9(2)$ & $-56.6(2)$ & $-65.9(2)$ & $-77.1(2)$ \\
N1-C6-C13-C18 & $111.9(1)$ & $129.6(2)$ & $119.8(2)$ & $108.2(2)$ \\
\hline
\end{tabular}

Nitrogen and sulfur atoms as acceptors and hydrogen atoms directly bonded to carbon atoms as donors, are engaged in weak intermolecular hydrogen bonds. Parameters of these interactions are listed in Table II. In the crystal structure of $\mathbf{3 S}$ carbon atoms of all three rings are engaged in intermolecular contacts, whereas in $\mathbf{4 S}$ only carbon atoms of aromatic rings and the methyl group at $\mathrm{C} 4$ atom. Substituents at aromatic ring are not engaged in any intermolecular interactions. There is an oxygen atom in the structure of $\mathbf{4 S}$, which could be an acceptor in hydrogen bonds, but in the presented crystal structure is not involved in any intermolecular hydrogen bonds.

Efflux modulating effects. The efflux-modulating effects of 1S-9S and 1Se-9Se were investigated in the sensitive parental (PAR) and resistant (MDR) mouse T-lymphoma cells overexpressing ABCB1 using the standard R123 functional assay (17). The results are expressed as the fluorescence activity ratio (FAR) values, which represent the accumulation of R123 in L5178Y-MDR and L-5178Y-PAR cells (Figure 3). When FAR value is higher than one, the modulation of ABCB1 occurs, while FAR value that is 

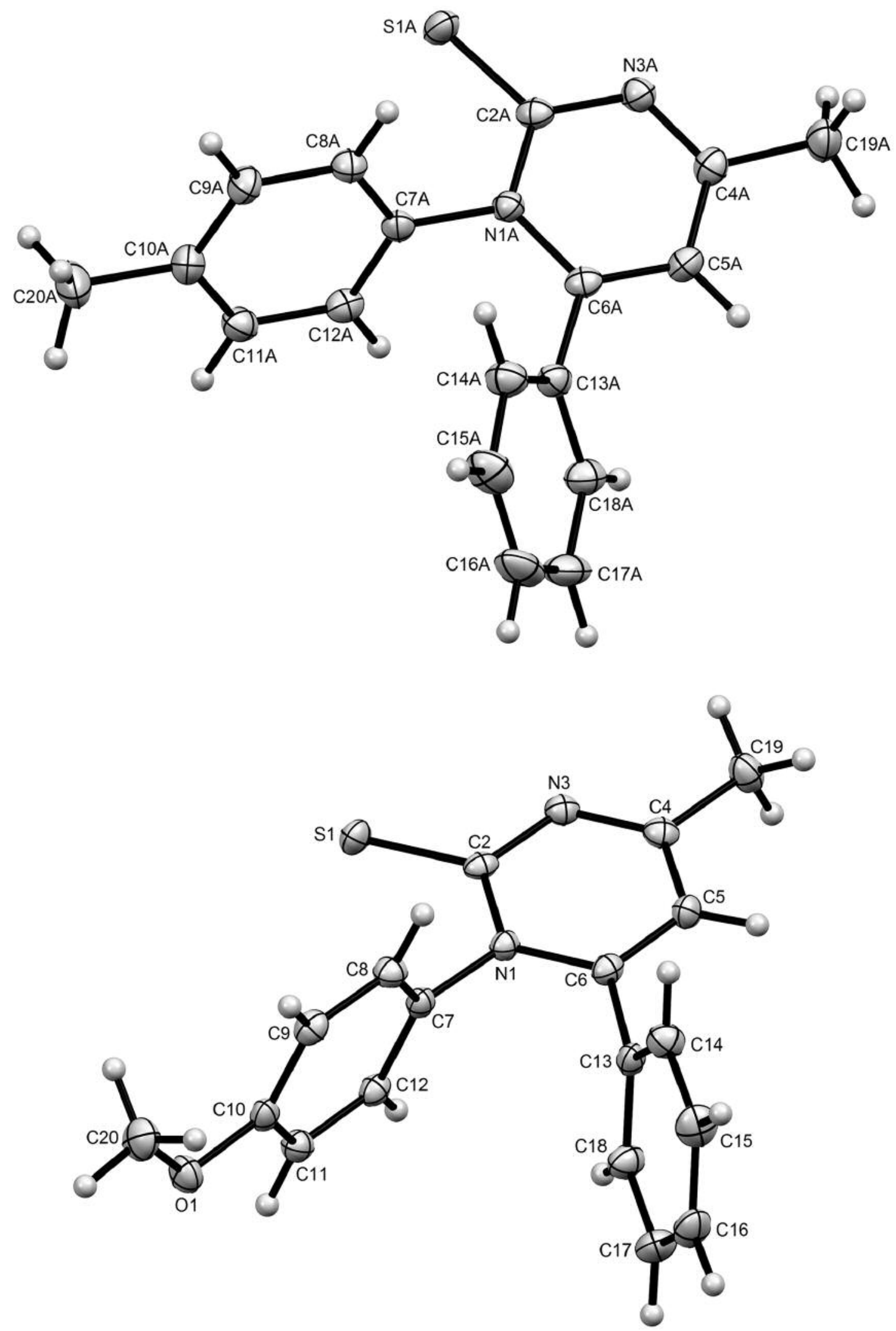

Figure 2. The molecular structures of $\mathbf{3 S}$ (molecule A) and $4 \mathrm{~S}$ in the crystalline state. 
Table II. Parameters of weak intermolecular hydrogen bonds.

\begin{tabular}{|c|c|c|c|c|c|}
\hline Comp. & $\mathrm{D}-\mathrm{H} \cdots \mathrm{A}$ & $\mathrm{H} \ldots \mathrm{A}[\AA]$ & $\mathrm{D} \ldots \mathrm{A}[\AA ̊]$ & $\mathrm{D}-\mathrm{H} \cdots \mathrm{A}\left[{ }^{\circ}\right]$ & Symmetry codes \\
\hline \multirow[t]{9}{*}{$3 S$} & C5A-H3A...N3B & 2.45 & $3.383(2)$ & 166 & $\mathrm{x},-\mathrm{y}+1 / 2, \mathrm{z}+1 / 2$ \\
\hline & C5B-H3B...N3A & 2.74 & $3.558(2)$ & 148 & $x-1,-y+1 / 2, z-1 / 2$ \\
\hline & $\mathrm{C} 5 \mathrm{~B}-\mathrm{H} 3 \mathrm{~B} \cdots \mathrm{S} 1 \mathrm{~A}$ & 2.78 & $3.629(2)$ & 150 & $x-1,-y+1 / 2, z-1 / 2$ \\
\hline & C8B-H8B...N3B & 2.65 & $3.353(2)$ & 131 & $-\mathrm{x},-\mathrm{y},-\mathrm{z}$ \\
\hline & C8B-H8B...S1B & 2.82 & $3.757(2)$ & 170 & $-\mathrm{x},-\mathrm{y},-\mathrm{z}$ \\
\hline & C11A-H11A $\cdots N 3 A$ & 2.74 & $3.331(2)$ & 121 & $x,-y+1 / 2, z+1 / 2$ \\
\hline & C12A-H12A...S1A & 3.08 & $3.969(2)$ & 157 & $x,-y+1 / 2, z+1 / 2$ \\
\hline & C16B-H16B...S1B & 3.02 & $3.720(2)$ & 132 & $\mathrm{x}-1, \mathrm{y}, \mathrm{z}$ \\
\hline & C17B-H17B $\cdots S 1 A$ & 2.83 & $3.708(2)$ & 154 & $\mathrm{x}-1, \mathrm{y}, \mathrm{z}$ \\
\hline \multirow[t]{4}{*}{$4 S$} & C9-H9...N3 & 2.76 & $3.471(2)$ & 134 & $-x+1,-y,-z+1$ \\
\hline & $\mathrm{C} 12-\mathrm{H} 12 \cdots \mathrm{N} 3$ & 2.52 & $3.363(2)$ & 152 & $-x+1,-y+1,-z+1$ \\
\hline & $\mathrm{C} 16-\mathrm{H} 16 \cdots \mathrm{N} 3$ & 2.74 & $3.637(2)$ & 163 & $x+1,-y+1 / 2, z+1 / 2$ \\
\hline & C19-H19A...S1 & 3.03 & $3.948(2)$ & 160 & $\mathrm{x},-\mathrm{y}+1 / 2, \mathrm{z}+1 / 2$ \\
\hline
\end{tabular}

higher than ten implicates strong modulation (26). The modulating effect was observed for almost all 1,6-diphenyl$2[1 H]$-pyrimidinethione/selenone derivatives (1-4), but only five compounds were more effective than the reference inhibitor verapamil and two of them (3S and $4 \mathrm{~S})$ showed strong modulation of ABCB1 at $20 \mu \mathrm{M}$. Other 1,4-diphenyl$2[1 H]$-pyrimidinethione/selenone derivatives (5-8) and thiohydantoin/selenohydantoin derivative (9) displayed lower activity than verapamil at $20 \mu \mathrm{M}$. The tested compounds had no efflux pump inhibiting effect at $2 \mu \mathrm{M}$.

Cytotoxic and antiproliferative effects. All compounds were examined for their cytotoxic effect in sensitive (PAR) and resistant (MDR) mouse T-lymphoma cells (17). As shown in Table III, all selenium analogues displayed cytotoxicity in both cell lines. Almost all sulfur analogues with the exception of two (5S and $\mathbf{9 S}$ ) showed no cytotoxic effect $\left(\mathrm{IC}_{50}>100 \mu \mathrm{M}\right)$ in the mouse $\mathrm{T}-1 y m p h o m a$ cell lines.

The antiproliferative activity of the presented compounds was investigated in sensitive (PAR) and resistant (MDR) mouse T-lymphoma cells (Table III) (27). The tested selenium analogues (1Se-9Se) showed significant antiproliferative profiles with $\mathrm{IC}_{50}$ in the range 0.9-1.7 $\mu \mathrm{M}$ for 1Se-4Se, 2.0-4.5 $\mu \mathrm{M}$ for 5Se-9Se. The sulfur analogues displayed much weaker activity from 35 to over $100 \mu \mathrm{M}$ except for $\mathbf{5 S}$ and $\mathbf{9 S}$.

Checkerboard combination assay. For compounds with efficient antiproliferative activity (1Se-9Se, 5 S and 9S), their ability to make MDR cells more susceptible to anticancer drug action was assessed using checkerboard combination assay. These compounds were tested together with the anticancer drug doxorubicin in order to get information about the nature of interactions between them (Table IV). In Table IV the best combination ratios of doxorubicin and tested compounds are presented. Combination index (CI) in the third column (Table IV) is based on the $50 \%$ of the growth inhibition dose $\left(\mathrm{ED}_{50}\right)$. The nature of interactions is determined on the basis of the CI value as a synergism $(\mathrm{CI}<1)$, antagonism $(\mathrm{CI}>1)$ or additive effect $(\mathrm{CI}=1)(28)$.

\section{Discussion}

Previously, several classes of compounds have been described as cytotoxic agents, adjuvants in combination with doxorubicin, ABCB1 modulators and apoptosis inducers, such as phenothiazines (29), steroidal compounds (30) and hydantoin derivatives (31). The presented compounds showed different biological activities. The analyzed compounds contain two aromatic rings in three different locations: (i) 1-4 possess the closest phenyl substituents, in $\mathrm{N} 1$ and $\mathrm{C} 6$ positions of 2[1H]-pyrimidinethione/selenone ring; (ii) 5-8 have the most distant phenyl substituents, in N1 and $\mathrm{C} 4$ positions of 2[1H]-pyrimidinethione/selenone ring and (iii) 9 contains the distant phenyl substituent at N3 and benzylidene substituent at $\mathrm{C} 5$ of 2-thio/selenohydantoin ring (Figure 1). The positions of the aromatic rings and the presence of sulfur or selenium atom are connected with biological activities.

The results obtained for the modulation of ABCB1 mediated efflux showed the best activity for sulfur analogues with phenyl substituent at neighboring atoms (N1 and C6) defined as location (i). These compounds showed also no cytotoxic effects in both cell lines (PAR and MDR). A deeper insight into the structural properties of the 1,6diphenylpyrimidinethione derivatives $(\mathbf{1 S}, \mathbf{3 S}, \mathbf{4 S})$ using the $\mathrm{X}$-ray crystal structure analysis allowed us to determine the mutual orientation of the rings. Compound $4 \mathrm{~S}$ with highest activity towards inhibition of ABCB1 showed the conformation with aromatic rings the closest to perpendicular 


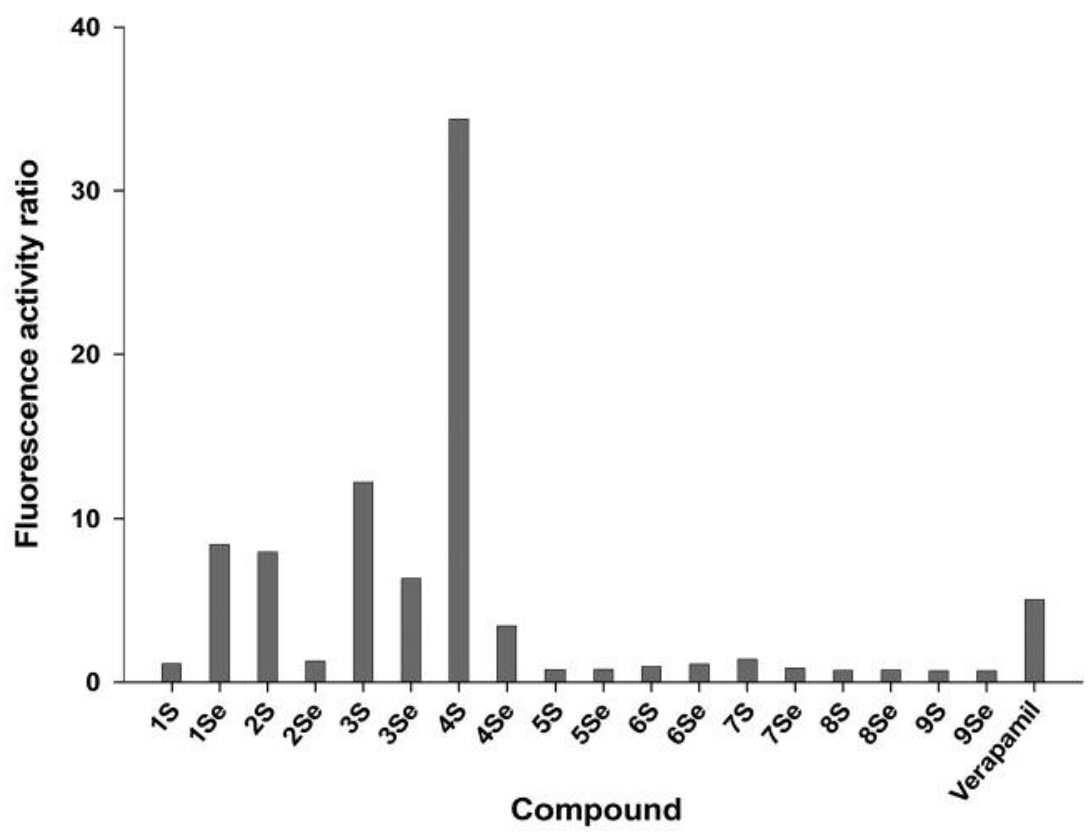

Figure 3. Rhodamine 123 retention in the presence of the compounds at $20 \mu \mathrm{M}$ and verapamil at $20 \mu \mathrm{M}$ as a positive control on multidrug-resistant T-lymphoma cells (MDR).

to the plane of $2[1 H]$-pyrimidinethione ring. Other compounds possessed these rings more twisted. Compound 1S, containing unsubstituted aromatic rings, was not more active than verapamil, while introducing the substituent to aromatic ring at $\mathrm{N} 1$ atom increased this activity. The introduction of an electron-withdrawing substituent, namely chlorine atom (2S), led to a 7 -fold increase in the efflux modulatory effect. However, an electron-donating substituent in aromatic ring, namely methyl group (3S), increased 11fold the efflux modulatory effect, while methoxy group (4S), a stronger electron-donating substituent increased 30-fold ABCB1 inhibiting activity.

Interestingly, the replacement of sulfur atom with selenium atom increased almost 8-fold the activity of 1Se in comparison to $\mathbf{1 S}$. The comparison of molecular geometries of these two compounds did not show significant differences (22). In this case the presence of selenium atom seems to be important for biological activity. However, the chlorine substituent in aromatic ring decreased the capacity of 2Se to inhibit the ABCB1 efflux pump, giving a value of FAR almost the same as for $\mathbf{1 S}$. The introduction of a methyl substituent to the aromatic ring in 1Se (compound 3Se) improved activity in comparison to $\mathbf{2 S e}$, while the presence of methoxy group in 4 Se caused a lower activity than verapamil.

Cytotoxic activity among investigated compounds is mainly related to the presence of the selenium atom. The role of the aromatic rings' locations seems to be less important.
All selenium analogues displayed high cytotoxic effects in both sensitive and resistant cell lines. Only two sulfur analogues (5S and 9S) showed cytotoxic activity. Sulfur analogues with modulating effect on ABCB1 (1S-4S) were not cytotoxic on the tested lines.

The capacity of the investigated compounds regarding antiproliferative activity is correlated with the cytotoxicity effect: all cytotoxic selenium analogues displayed antiproliferative activity with $\mathrm{IC}_{50}$ in the range of $0.9-6 \mu \mathrm{M}$ in both cell lines (PAR and MDR). The sulfur analogues, excluding 5S and 9S, showed 10-fold weaker antiproliferative activity. The combination assay with doxorubicin on MDR cells for compounds with potent antiproliferative activity showed that selenium derivatives with (i) location of the rings (1Se-4Se) displayed antagonism, derivatives with (ii) location (5Se-8Se) moderate antagonism/synergism, while the third group (iii), namely derivative of 2-thio/selenohydantoin (9S, 9Se), synergism.

To summarize, the presented results allowed us to identify new compounds (1S-4S) showing potency to inhibit the cancer MDR efflux pump ABCB1. The introduction of an electron-donating substituent in the phenyl ring at $\mathrm{N} 1$ atom increased the activity. These results point out the 1,6diphenyl-2[1H]-pyrimidinethione scaffold for further structural modifications in order to improve the efflux modulation on ABCB1. For the most active compound (4S) the mutual orientations of aromatic and pyrimidinethione rings show the closest angles to 90 degrees between the 
Table III. Cytotoxic and antiproliferative effects of the compounds on sensitive L5178Y parental (PAR) and resistant (MDR) mouse T-lymphoma cells.

\begin{tabular}{|c|c|c|c|c|}
\hline \multirow[t]{3}{*}{ Compound } & \multicolumn{4}{|c|}{$\mathrm{IC}_{50}[\mu \mathrm{M}]$} \\
\hline & \multicolumn{2}{|c|}{ Cytotoxic effect } & \multicolumn{2}{|c|}{ Antiproliferative effect } \\
\hline & PAR & MDR & PAR & MDR \\
\hline 1S & $>100$ & $>100$ & $53 \pm 1.99$ & $54.3 \pm 0.85$ \\
\hline 1Se & $1.04 \pm 0.09$ & $1.29 \pm 0.02$ & $1.4 \pm 0.26$ & $1.5 \pm 0.12$ \\
\hline $2 S$ & $>100$ & $>100$ & $47 \pm 1.99$ & $36 \pm 2.22$ \\
\hline $2 \mathrm{Se}$ & $0.77 \pm 0.77$ & $1.08 \pm 0.03$ & $0.9 \pm 0.1$ & $1.14 \pm 0.05$ \\
\hline $3 S$ & $>100$ & $>100$ & $47 \pm 0.58$ & $64 \pm 1.99$ \\
\hline $3 \mathrm{Se}$ & $0.77 \pm 0.09$ & $1.06 \pm 0.05$ & $1.17 \pm 0.03$ & $1.7 \pm 0.09$ \\
\hline $4 S$ & $>100$ & $>100$ & $50 \pm 1.36$ & $56 \pm 2.64$ \\
\hline $4 \mathrm{Se}$ & $0.79 \pm 0.01$ & $1.09 \pm 0.01$ & $1.15 \pm 0.03$ & $1.58 \pm 0.04$ \\
\hline $5 S$ & $8.17 \pm 0$ & $15 \pm 1.04$ & $8.6 \pm 0.24$ & $12.9 \pm 0.15$ \\
\hline $5 \mathrm{Se}$ & $1.26 \pm 0.04$ & $1.48 \pm 0.08$ & $2.2 \pm 0.14$ & $2.61 \pm 0.08$ \\
\hline $6 \mathrm{~S}$ & $>100$ & $>100$ & $35 \pm 5.43$ & $54 \pm 2.96$ \\
\hline 6Se & $3.1 \pm 0.22$ & $4.1 \pm 0.12$ & $3.4 \pm 0.27$ & $4.1 \pm 0.16$ \\
\hline $7 \mathrm{~S}$ & $>100$ & $>100$ & $82 \pm 2.88$ & $>100$ \\
\hline 7Se & $2.03 \pm 0.09$ & $2.9 \pm 0.07$ & $2 . \pm 0.19$ & $2.13 \pm 0.05$ \\
\hline $8 S$ & $>100$ & $>100$ & $85 \pm 4$ & $>100$ \\
\hline $8 \mathrm{Se}$ & $4.39 \pm 0$ & $4.4 \pm 0.26$ & $3.6 \pm 0.22$ & $4.51 \pm 0.07$ \\
\hline 9S & $14.5 \pm 0.34$ & $14 \pm 2.48$ & $4.5 \pm 0.16$ & $8 \pm 1.45$ \\
\hline 9Se & $5.5 \pm 0.49$ & $9 \pm 2.81$ & $6 \pm 0.37$ & $4 \pm 0.73$ \\
\hline Doxorubicin & $0.7 \pm 0.56$ & $2.14 \pm 0.76$ & $0.28 \pm 0.06$ & $1.75 \pm 0.38$ \\
\hline
\end{tabular}

rings. All selenium analogues showed very potent cytotoxic and antiproliferative activities. Two derivates of the 1,4diphenyl-2[1H]-pyrimidineselenone (5Se, 7Se) exerted a synergistic effect in combination with doxorubicin. Both 2thiohydantoin and 2-selenohydantoin derivatives $(\mathbf{9 S}, \mathbf{9 S e})$ improved the cytotoxicity of doxorubicin synergistically.

\section{Acknowledgements}

The Authors would like to thank Prof. Jadwiga Handzlik for her comprehensive discussion. The work was supported by Pedagogical University of Cracow (BS-465/G/2018).

\section{References}

1 WHO Media Centre, Fact sheet $N^{\circ} 297$, February 2017. http://www.who.int/mediacentre/factsheets/fs297/en/.

2 Linton KJ and Higgins CF: Structure and function of $\mathrm{ABC}$ transporters: the ATP switch provides flexible control. Pflugers Arch 453: 555-567, 2007

3 Hegedüs C, Truta-Feles K, Antalffy G, Várady G, Német K, Ozvegy-Laczka C, Kéri G, Orfi L, Szakács G, Settleman J, Váradi A and Sarkadi B: Interaction of the EGFR inhibitors gefitinib, vandetanib, pelitinib and neratinib with the ABCG2 multidrug transporter: Implications for the Emergence and
Table IV. Type of interaction between compounds and doxorubicin against multidrug-resistant (MDR) mouse T-lymphoma cells.

\begin{tabular}{lccc}
\hline Compound & Best ratio $^{\mathrm{a}}$ & $\mathrm{CI}$ at ED50 & Interaction \\
\hline $\mathbf{1 S e}$ & $2: 2.5$ & $1.6 \pm 0.26$ & Antagonism \\
$\mathbf{2 S e}$ & $1: 10$ & $1.4 \pm 0.18$ & Moderate antagonism \\
$\mathbf{3 S e}$ & $2: 2.5$ & $2.4 \pm 075$ & Antagonism \\
$\mathbf{4 S e}$ & $4: 10$ & $1.6 \pm 0.49$ & Antagonism \\
$\mathbf{5 S}$ & $16: 12.5$ & $1.5 \pm 0.14$ & Antagonism \\
$\mathbf{5 S e}$ & $2: 5$ & $0.8 \pm 0.1$ & Moderate synergism \\
$\mathbf{6 S e}$ & $8: 5$ & $1.3 \pm 0.14$ & Moderate antagonism \\
$\mathbf{7 S e}$ & $8: 2.5$ & $0.8 \pm 0.13$ & Moderate synergism \\
$\mathbf{8 S e}$ & $8: 5$ & $1.0 \pm 0.18$ & Nearly additive \\
$\mathbf{9 S}$ & $1: 12.5$ & $0.68 \pm 0.06$ & Synergism \\
$\mathbf{9 S e}$ & $2: 25$ & $0.8 \pm 0.14$ & Moderate synergism \\
\hline
\end{tabular}

a Data are shown as the best combination ratio between doxorubicin and tested compounds. ${ }^{b}$ Combination index $(\mathrm{CI})$ values at the $50 \%$ growth inhibition dose $\left(\mathrm{ED}_{50}\right)$ were determined by the CompuSyn software to plot four to five data points at each ratio. CI values were calculated by means of the median-effect equation, where $\mathrm{CI}<1, \mathrm{CI}=1$ and $\mathrm{CI}>1$ represent synergism, additive effect (i.e., no interaction), and antagonism, respectively.

reversal of cancer drug resistance. Biochem Pharmacol 84: 260267, 2012.

4 Gottesman MM, Fojo T and Bates SE: Multidrug resistance in canser: role of ATP-dependent transporters. Nat Rev Cancer 2: 45-48, 2002.

5 Tsuruo T, Iida H, Tsukagoshi S and Sakurai Y: Overcoming of vincristine resistance in $\mathrm{P} 388$ leukemia in vivo and in vitro through enhanced cytotoxicity of vincristine and vinblastine by verapamil. Cancer Res 41: 1967-1972, 1981.

6 Foxwell BM, Mackie A, Ling V and Ryffel B: Identification of the multidrug resistance-related $\mathrm{P}$-glycoprotein as a cyclosporine binding protein. Mol Pharmacol 36: 543-546, 1989.

7 Mickisch GH, Noordzij MA, Gaast A, Gebreamlack P, Köhrmann KU, Mogler-Drautz E, Kupper H and Schröder FH: Dexverapamil to modulate vinblastine resistance in metastatic renal cell carcinoma. J Cancer Res Clin Oncol 121(Suppl 3): R11-R16, 1995.

8 Boesch D, Gaveriaux C, Jachez B, Pourtier-Manzanedo A, Bollinger $\mathrm{P}$ and Loor $\mathrm{F}$ : In vivo circumvention of $\mathrm{P}$ glycoprotein-mediated multidrug resistance of tumor cells with SDZ PSC 833. Cancer Res 51: 4226-4233, 1991.

9 Palmeira A, Sousa E, Vasconcelos MH and Pinto MM: Three decades of P-gp inhibitors: skimming through several generations and scaffolds. Curr Med Chem 19(13): 1946-2025, 2012.

10 Nobili S, Landini I, Giglioni B and Mini E: Pharmacological strategies for overcoming multidrug resistance. Curr Drugs Targets 7: 861-879, 2006.

11 Chae SW, Woo S, Park JH, Kwon Y, Na Y and Lee HJ: Xanthone analogues as potent modulators of intestinal Pglycoprotein. Eur J Med Chem 93: 237-245, 2015.

12 Chae SW, Lee J, Park JH, Kwon Y, Na Y and Lee HJ: Intestinal P-glycoprotein inhibitors, benzoxanthone analogues. J Pharm Pharmacol 70: 234-241, 2018. 
13 Handzlik J, Spengler G, Mastek B, Dela A, Molnar J, Amaral L and Kieć-Kononowicz K: 5-Arylidene(thio)hydantoin derivatives as modulators of cancer efflux pump. Acta Pol Pharm-Drug Res 69: 149-153, 2012.

14 Żesławska E, Kinces A, Spengler G, Nitek W, Wyrzuc K, KiećKononowicz K and Handzlik J: The 5-aromatic hydantoin-3acetate derivatives as inhibitors of the tumour multidrug resistance efflux pump P-glycoprotein (ABCB1): synthesis, crystallographic and biological studies. Bioorg Med Chem 24: 2815-2822, 2016.

15 Chen CY, Liu NY, Lin HC, Lee CY, Hung CC and Chang CS: Synthesis and bioevaluation of novel benzodipyranone derivatives as P-glycoprotein inhibitors for multidrug resistance reversal agents. Eur J Med Chem 118: 219-229, 2016.

16 Paterna A, Khonkarn R, Mulhovo S, Moreno A, Madeira G, Baubichon-Cortay H, Falson P and Ferreira M-JU: Monoterpene indole alkaloid azine derivatives as MDR reversal agents. Bioorg Med Chem 26: 421-434, 2018.

17 Dominguez-Alvarez E, Gajdacs M, Spengler G, Palop JA, Marć MA, Kieć-Kononowicz K, Amaral L, Molnar J, Jacob C, Handzlik J and Sanmartin C: Identification of selenocompounds with promising properties to reverse cancer multidrug resistance. Bioorg Med Chem Lett 26: 2821-2824, 2016.

18 Gajdacs M, Spengler G, Sanmartin C, Marć MA, Handzlik J and Dominguez-Alvarez E: Selenoesters and selenoanhydrides as novel multidrug resistance reversing agents: A confirmation study in a colon cancer MDR cell line. Bioorg Med Chem Lett 27: 797-802, 2017.

19 Wong ILK, Wang B-C, Yuan J, Duan L-X, Liu Z, Liu T, Li XM, Hu X, Zhang X-Y, Jiang T, Wan S-B and Chow LMC: Potent and nontoxic chemosensitizer of P-glycoprotein-mediated multidrug resistance in cancer: synthesis and evaluation of methylated epigallocatechin, galootechin and dihydromyricetin derivatives. J Med Chem 58: 4529-4549, 2015.

20 Żylewska A, Tejchman W, Korohoda MJ and Żylewski M: Synthesis of 1,4,6-trisubstituted 2[1H]-Pyrimidine-selonones. Heterocycles 60(12): 2749-2760, 2003.

21 Korohoda MJ: Introduction of selenium into heterocycliccompounds.1. Synthesis of 3-aryl-2-selenohydantoins with double-bond at C-5. Pol J Chem 54: 683-692, 1980.

22 Żesławska E, Korona-Głowniak I, Szczesio M, Olczak A, Żylewska A, Tejchman W and Malm A: Structural analysis and antimicrobial activity of $2[1 H]$-pyrimidinethione/selenone derivatives. J Mol Struct 1142: 261-266, 2017.
23 Sheldrick GM: Crystal structure refinement with SHELXL. Acta Cryst C 71: 3-8, 2015.

24 Macrae CF, Edgington PR, McCabe P, Pidcock E, Shields GP, Taylor R, Towler M and van de Streek J: Mercury: Visualization and Analysis of Crystal Structures. J Appl Cryst 39: 453-457, 2006.

25 Cornwell MM, Pastan I and Gottesman MM: Certain calcium channel blockers bind specifically to multidrug-resistant human $\mathrm{KB}$ carcinoma membrane vesicles and inhibit drug binding to $\mathrm{P}$ glycoprotein. J Biol Chem 262: 2166-2170, 1987.

26 Voigt B, Coburger C, Molnar J and Hilgeroth J: Structure-activity relationships of novel $\mathrm{N}$-acyloxy-1,4-dihydropyridines as $\mathrm{P}$ glycoprotein inhibitors. Bioorg Med Chem 15: 5110-5113, 2007.

27 Poljarević JM, Tamás Gál G, May NV, Spengler G, Dömötör O, Savić AR, Grgurić-Šipka S and Enyedy EA: Comparative solution equilibrium and structural studies of half-sandwich ruthenium(II)( $\eta 6$-toluene) complexes of picolinate derivatives. J Inorg Biochem 181: 74-85, 2018.

28 Chou TC: Theoretical basis, experimental design, and computerized simulation of synergism and antagonism in drug combination studies. Pharm Rev 58: 621-681, 2006.

29 Takács D, Csonka Á, Horváth Á, Windt T, Gajdács M, Riedl Z, Hajós G, Amaral L, Molnár J and Spengler G: Reversal of ABCB1-related Multidrug resistance of colonic adenocarcinoma cells by phenothiazines. Anticancer Res 35: 3245-3251, 2015.

30 Csonka Á, Hamdoun S, Spengler G, Martins A, Vincze I, Efferth $\mathrm{T}$ and Molnár J: Substituted steroidal compounds containing amino and amido groups reverse multidrug resistance of mouse T-lymphoma and two human prostate cancer cell lines in vitro. Anticancer Res 35: 2105-2112, 2015.

31 Spengler G, Handzlik J, Ocsovszki I, Viveiros M, KiecKononowicz K, Molnar $\mathrm{J}$ and Amaral L: Modulation of multidrug efflux pump activity by new hydantoin derivatives on colon adenocarcinoma cells without inducing apoptosis. Anticancer Res 31: 3285-3288, 2011. 